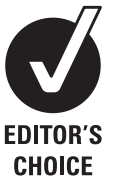
Professor Øystein Kravdal, Department of Economics, University of Oslo, PO Box 1095 , Blindern, Oslo 0317, Norway; okravdal@econ.uio.no

Accepted 19 September 2009 Published Online First 23 October 2009

\title{
The importance of community education for individual mortality: a fixed-effects analysis of longitudinal multilevel data on 1.7 million Norwegian women and men
}

\author{
Øystein Kravdal
}

\begin{abstract}
Background Earlier investigations have shown mortality effects of community socio-economic resources. However, the sex differences have not been clear, and the estimates may well have been biased because of inadequate control for community factors affecting both the socio-economic resources and mortality. The objective of this study was to see whether any effects appeared when time-invariant community characteristics were controlled by including community dummies (fixed effects) and whether there were any differences between women and men.
\end{abstract}

Methods Discrete-time hazard models for all-cause mortality were estimated for 1981-2002 for all Norwegians aged 60-89, using register data. There were 730000 deaths among 1.7 million people observed during 19 million person-years. Average education was measured for 433 municipalities for each of the 22 years. Results According to the simplest models, a high average education in the municipality is associated with increased mortality. Control for population size (timeaveraged) reversed the effects. Inclusion of municipality dummies instead of population size, to control also for additional unobserved time-invariant municipality characteristics, gave very different results: the effects were even stronger for men, while those for women were no longer significant. The results were quite robust to alternative specifications, including the use of a lagged average-education variable.

Conclusion The study supports the idea that community socio-economic resources may affect mortality and suggests that sex differentials may deserve more attention. It also illustrates the importance of controlling for time-invariant community factors. Unless these can be easily measured, in future investigations one may consider establishing longitudinal data and using a fixedeffects approach such as that used here.

Several studies have suggested that a person's mortality is influenced by the socio-economic resources in the community, given his or her own resources. ${ }^{12}$ Such effects have been seen even in egalitarian Nordic countries with a public healthcare system. ${ }^{3-10}$ However, the effects tend to be rather weak, and there is much uncertainty about their variation. In particular, some authors have found no difference between the sexes, 57 11-13 while others have found that women's health is most affected ${ }^{14-16}$ or that men's is most affected. ${ }^{17}$

One potential problem with all such studies is that the community socio-economic resources may be determined partly by community characteristics that also affect individual mortality and that are omitted from the model. While the researcher may know, for example, whether the place is urban or rural, and include that in the model, there are a number of other factors, for example of environmental, political or cultural character, that may be difficult to measure or not available. However, if the data have a longitudinal design, in the sense that the community factor in focus is measured more than once, one can control for at least the time-invariant components of the unobserved community factors by adding 0/1-dummies for each community. These dummies would typically be referred to as 'fixed-effects' and the model characterised as a 'fixed-effects model' in economics and other social sciences, where various types of such models are often used to take unobserved factors into account. ${ }^{18-22}$ In epidemiological research on effects of community resources, regional dummies have been included in purely ecological models or to pick up unobserved factors at a higher level than the community variables in focus, ${ }^{23-27}$ but rarely to control for unobserved factors at the same level as the key community variables. An exception is a recent study on how psychological distress was affected by social capital measured in 58 US Metropolitan Statistical Areas in three successive years. ${ }^{28}$ Dummies representing that level of aggregation were included, which gave very different results, and the authors pointed out that this was a novel approach. In contrast, so-called 'randomeffects' models are popular in social epidemiology, but these are based on an assumption that the unobserved community factors are uncorrelated with the socio-economic or other community covariates of interest (see below).

In the present study, an extraordinarily large Norwegian data set that includes individual migration histories, and therefore allows fixed-effects analysis, was used. The two main objectives were to see whether the fixed-effects analysis gave results that were markedly different from those obtained with a more standard analysis (ie, without community dummies), and whether there were any sex differentials in the effect of community socioeconomic resources according to either approach. The municipality, which is the lowest politicaladministrative unit in the country and the lowest unit defined in the data, was the level of aggregation The focus was on mortality at age 60-89, when most deaths occur: currently, only $7 \%$ die earlier. ${ }^{29}$ 
Education was used as the only indicator of socio-economic resources. It has attracted much attention as an individuallevel health determinant, ${ }^{30-32}$ and has also been included as a community-level variable in multilevel research-alone or in combination with other community variables ${ }^{63-36}$ or as one of several factors in a socio-economic index ${ }^{11} 37$ 38-though community income measures have been more often used. Education and income are of course closely correlated, and especially at the aggregate level, ${ }^{39}$ so the estimated effects of education also reflect income effects. More precisely, community education affects mortality partly through community income and partly through various non-economic pathways (see Discussion). In addition, community education is to some extent determined by community income.

It is not obvious which age group one should choose when calculating the average education in the municipality. Some effects of community education may involve people of the same age as the individuals under investigation, while others may involve older people or those in working ages. This issue has received very little attention in the literature. In the present study, two alternatives were tried. In addition, it was experimented with lagged variables, since it may take some time before a social environment leaves a visible imprint on mortality. For example, a person's chance of dying in a particular year is likely to depend on his or her lifestyle in earlier years, which may be influenced by the resources of other individuals with whom the person interacted at that time. Some models included the average education 10 or 20 years earlier, in the municipality where the person lived at that time, rather than the current average-education 'exposure.' Lagged community variables have been considered only in a few earlier studies. ${ }^{40} 41$

\section{MATERIAL AND METHODS \\ Data}

With approval from the Data Inspectorate and the Regional Ethical Committee, data covering the period up through 2002 were extracted from the Norwegian population register, which includes everyone who has ever lived in Norway after 1960, and from Statistics Norway's education files based on schools' reporting since 1980 and earlier censuses. For each person, there is information on the highest educational level achieved as of 1 October every year from 1980 and as of 1970, municipality of residence every month since 1964, dates of any in- and outmigration, and date of death. For confidentiality reasons, the municipalities of residence could not be identified but were defined by an internally consistent set of codes. Using these codes, the average education was computed for each year and each municipality from the individual data, and then added to the individual records, giving a full history of (current or lagged) average-education exposure for each person. Population size was computed in a similar way (see below).

Norway currently has 431 municipalities, but there were 433 at the time when these data were compiled. The size of the municipalities varies greatly. Oslo, the capital, has about half a million inhabitants, and there are four other large urban municipalities with a population of 100000-250000. Among the other municipalities, the average population size is about 7000, with a variation from 200 to 75000 .

\section{Estimation of discrete-time hazard models}

For each person, a series of 1-year observations was created, starting January the year the person turned 60 or, if born before 1921, January 1981 (except in the analyses where average education was lagged 20 years; see below). The end of follow-up was in 2002, at age 89 , or at the time of death or last emigration, whichever came first. These 1 -year observations included various variables defined at the start of the year, and the outcome variable was whether the person died within the year. All observations were pooled, and sex-specific logistic models were estimated from the resulting data set, using SAS software (SAS Institute, Cary, North Carolina).

Two types of models were estimated. One was of the form:

1. Equation $\left(\mathrm{p}_{\mathrm{ijt}} /\left(1-\mathrm{p}_{\mathrm{ijt}}\right)\right)=\boldsymbol{\beta}_{1} \mathbf{X}_{\mathrm{ijt}}+\boldsymbol{\beta}_{2} \mathbf{Z}_{\mathrm{jt}}+\boldsymbol{\beta}_{3} \mathbf{T}_{\mathrm{t}}$,

where $p_{i j t}$ is the probability that person $i$ alive in municipality $j$ at the beginning of year $t$ dies within that year, $\mathbf{X}_{\mathrm{ijt}}$ is a vector of individual time-varying characteristics (education, which in practice varies very little over time, and age), $\mathbf{Z}_{\mathrm{jt}}$ is a vector of municipality characteristics (average education and in some models population size, the latter defined as time-invariant within $j$, though $j$ of course varies with $t$ for an individual), $\mathbf{T}_{\mathrm{t}}$ is a vector of dummies representing 1-year periods, and $\boldsymbol{\beta}_{1}, \boldsymbol{\beta}_{2}$ and $\boldsymbol{\beta}_{3}$ are effect vectors. One-year observations starting when the person under consideration was temporarily abroad or before first immigration were ignored. In total, 917000 women experienced 344709 deaths during the 10.9 million person-years of follow-up, while the corresponding numbers for men were 807000,389140 , and 8.6 million.

The other type of model was similar, except that a vector of municipality dummies $\mathrm{Fj}$ (one dummy for each municipality except one arbitrarily chosen as a reference) was included to take into account that unobserved time-invariant municipality factors may affect both average education and individual mortality:

2. Equation $\left(\mathrm{p}_{\mathrm{ijt}} /\left(1-\mathrm{p}_{\mathrm{ijt}}\right)\right)=\boldsymbol{\beta}_{1} \mathbf{X}_{\mathrm{ijt}}+\boldsymbol{\beta}_{2} \mathbf{Z}_{\mathrm{jt}}+\boldsymbol{\beta}_{3} \mathbf{T}_{\mathrm{t}}+\boldsymbol{\beta}_{4} \mathbf{F}_{\mathrm{j}}$, Obviously, the $\mathbf{Z}$ vector cannot then include time-invariant variables, so the population size must be left out. Using this fixed-effects approach, the overall level (time-averages) of average education in the municipalities is absorbed into the municipality dummies, and the effect of average education is identified from the changes in average education and mortality within each municipality. As an example that may give some intuitive understanding of the approach, consider two persons with the same individual characteristics living in a given municipality in different years. If the difference in mortality between the person living there in the latest year and the person living there in the earliest year is most positive in the municipalities that have seen the largest increase in average education over that period, the estimate of the effect of average education will be positive (see simple discussion of the method elsewhere ${ }^{42}$ ). It may also be helpful to keep in mind that, according to the model, a man who experiences an immediate (and very hypothetical) one-unit change in average education in the municipality where he lives, with no individual changes taking place at the same time, will experience a change of $\boldsymbol{\beta}_{2}$ in his log-odds of dying. This change in mortality will also be experienced if he moves to another municipality with a one-unit higher average education and the same level of time-invariant unobserved characteristics.

As mentioned above, it is common when analysing mortality effects of community characteristics (using models such as (1)) to add a community-level random term that is intended to reflect time-invariant unobserved characteristics at that level, and that - as opposed to the municipality fixed effects in (2) - is assumed to be uncorrelated with the observed variables. In the multilevel epidemiological literature, this is usually called a 'random-' or 'mixed-effects model' (while many researchers in 
this area would refer not only to model (2), but also model (1) as a 'fixed-effects model' since all terms are 'fixed'). Inclusion of such a random term increases the standard errors of the community-level effects, while they in principle should have little impact on the point estimates unless there is much unexplained between-community variation. ${ }^{43}$ Random effects models are not estimated as part of this investigation. They are of little relevance given the focus on the possibility that certain unobserved factors may be correlated with the municipality covariates of interest, and there are large practical problems involved in fitting such models to a data set with as many observations as here.

\section{Variables \\ Individual}

For the years 1981-2002, the education variables referred to the highest level attained as of 1 October the previous year. Five educational levels were defined: (1) compulsory (10 years), (2) lower-secondary (11-12 years), (3) upper-secondary (13 years), (4) some college (14-17) and (5) higher education (18 years or more). ${ }^{44}$ Unknown (2\%) was a separate category. For earlier years (only relevant for models including lagged variables), education referred to the level attained by the 1970 census, which for the youngest may be lower than the current level. Age was included with 5-year categories. A finer categorisation gave the same results.

\section{Municipality variables}

Unless otherwise stated, education was averaged over all women and men of age 60-89 in the municipality in which the person lived at the beginning of the 1-year observation. It was calculated by summing over individual observations, using a continuous education variable that was set to $10,11,13,15$ and 18 years in the five categories. (Using 16 and 19 instead of 15 and 18 gave almost the same results.) However, some models included the average over the age group 30-89 instead, or the average 10 or 20 years earlier in the municipality where the person lived then. Adjustment for differences in sex and age distribution was attempted but gave the same results.

There was substantial variation in average education within and between municipalities, reflecting differences in the opportunities to take education (some time earlier) and in how attractive places are to persons at different educational levels. Within the entire sample, the minimum and maximum values were 10.1 and 13.1 years of education, the SD was 0.49 years, and the mean was 11.0 years. About $20 \%$ of the variance was within municipalities. To elaborate on the latter component, which is essential in the fixed-effects modelling, the average education in a municipality increased by 0.51 years over the period 1981-2002 (assuming a linear trend) as a national average. The SD of this trend (across municipalities) was 0.18 years of education, the minimum was -0.07 , and the maximum was 1.28 .

Also, the population size of the municipality, averaged over the years 1981-2002, was included in some models as a 10-level categorical variable. It was the only available indicator of how urban the municipality is, which is a factor that may affect both education and health, ${ }^{3}$ and which it seems reasonable to consider time-invariant during the period under analysis.

\section{RESULTS}

A significant negative effect of the current average education in the current municipality of residence appeared for both sexes in models including also individual age and education, period, and population size, but not municipality dummies (Model A, table 1). The control for population size was important, and more so for men than for women: in some large municipalities, there was both a generally high average education and a high mortality, and when this was not controlled for, an adverse effect of high average education appeared (Model B, table 1).

In the next step, municipality dummies were included in place of population size to pick up even more of the potentially confounding time-invariant factors. Once again, the estimate was pushed most markedly towards the negative for men, and a very sharp effect appeared (Model K, table 1). For women, the effect was no longer significant at the $5 \%$ level.

If these estimates are taken to reflect causal effects, the implication would be that a man who, for example, experiences a 0.5 -year increase in the average-education exposure while all other determinants of mortality remain constant would experience a mortality reduction of $17 \%\left(1-0.686^{* * 0.50}\right)$. The halfyear increase is chosen quite arbitrarily as an example, but it may be noted that it is close to the increase that on average has taken place within municipalities over the 22-year period, and also close to the between-municipality SD of average education. In comparison, if the estimates from the simpler model with control for only population size (Model A) are taken to reflect causal effects, the implication would be that a 0.5 -year increase in average education, everything else fixed, would reduce a man's mortality by only $2 \%\left(1-0.955^{* * 0.50}\right)$.

It did not matter much whether the average education was calculated for age 30-89 or age 60-89, neither in models of type 1 (compare models $\mathrm{A}$ and $\mathrm{C}$ in table 1 ) nor in models of type 2 (compare models $\mathrm{K}$ and $\mathrm{L}$ in table 1 ).

A similar pattern in the estimates appeared, in both types of models, when average education was lagged 10 years (compare models $\mathrm{A}$ and $\mathrm{F}$ and models $\mathrm{K}$ and $\mathrm{P}$ in table 2). The dummies then referred to the municipality where the person lived at that time. The results were also quite similar when a 20 -year lag was used, in which case the observation period had to be reduced to 1991-2002 (compare models $G$ and $H$ with model $A$, and models $\mathrm{Q}$ and $\mathrm{R}$ with model $\mathrm{K}$ ). It should be noted, however, that the effect for women almost attained significance at the $5 \%$ level in one of the model specifications, and that some CIs for women overlapped with those from corresponding models for men.

The results also appeared to be quite robust to various other alternative specifications (not shown in the tables). For example, similar effects were seen when the five largest or 100 smallest municipalities were excluded, when using the proportion highschool graduates rather than average years of education (the different scale taken into account), and when focussing on mortality at age 40-59 rather than 60-89.

\section{DISCUSSION \\ Empirical conclusions}

Estimates from models that included population size but not municipality dummies suggested an inverse relationship between individual mortality and community socio-economic resources, measured here by education. This accords with many other Nordic studies, which have usually focused on somewhat younger persons and have been based on economic community indicators rather than average education. The effect did not vary with sex. Earlier studies have provided mixed evidence about such sex differentials (as well as those in the effect of individual education $^{30}$ and another frequently studied community factor, social cohesion ${ }^{13} 16^{45-48}$ ). 
Table 1 Effects of average education in the municipality on individual mortality, according to various models, among women and men aged 60-89 in 1981-2002 (ORs with 95\% Cls)

\begin{tabular}{|c|c|c|}
\hline & Women & Men \\
\hline \multicolumn{3}{|l|}{ Models of type $1 \dagger$} \\
\hline $\begin{array}{l}\text { A: Includes current average education among persons } \\
\text { aged } 60-89 \text { in the current municipality of residence, } \\
\text { individual education } \dagger \text { and age, period and population size }\end{array}$ & $0.940^{* *}(0.928$ to 0.952$)$ & $0.955^{* *}(0.943$ to 0.966$)$ \\
\hline B: As for A, but without population size & $1.039 * *(1.031$ to 1.048$)$ & $1.098^{* *}(1.090$ to 1.107$)$ \\
\hline $\begin{array}{l}\text { C: As for } A \text {, but average education at age } 30-89 \text { instead } \\
\text { of } 60-89\end{array}$ & $0.927^{* *}(0.916$ to 0.939$)$ & $0.959 * *(0.948$ to 0.970$)$ \\
\hline \multicolumn{3}{|l|}{ Models of type 2} \\
\hline $\begin{array}{l}\text { K: Includes current average education among persons aged } \\
60-89 \text { in the current municipality of residence, individual } \\
\text { education and age, period and municipality dummies }\end{array}$ & $0.946^{*}(0.890$ to 1.005$)$ & $0.686^{* *}(0.648$ to 0.725$)$ \\
\hline $\begin{array}{l}\mathrm{L}: \text { As for } \mathrm{K} \text {, but average education at age } 30-89 \text { instead } \\
\text { of } 60-89\end{array}$ & $0.942(0.877$ to 1.012$)$ & $0.731^{* *}(0.682$ to 0.783$)$ \\
\hline
\end{tabular}

${ }^{*} \mathrm{p}<0.10 ;{ }^{* *} \mathrm{p}<0.001$.

†Effects of individual education: women: $1,0.826,0.782,0.704,0.688$; men: $1,0.836,0.816,0.693,0.603$.

A more important result, however, is that the estimated effects of the average education in the municipality were strongly dependent on whether time-invariant municipality characteristics were controlled for. A reverse relationship appeared only when population size was included. Inclusion of that variable made especially the estimates for men more negative. However, population size may not fully capture the extent to which the municipality has an urban character, and there may be other types of time-invariant factors affecting both average education and mortality, such as distance from major cities, access to natural resources and lifestyle traditions (partly reflecting the physical environment). When all this was picked up through the municipality dummies, the effects for men were further strengthened, while those for women became weaker.

In other words, a number of time-invariant and time-varying factors may affect both the socio-economic resources in the community and individual mortality. It has been shown here that failure to control for the former may lead to severely biased estimates. In future investigations, it may therefore be a good idea to try a longitudinal design that allows control for unob- served time-invariant factors (unless the potentially important time-invariant confounders can be easily measured of course). Further, the possibility of sex differentials seems to deserve more attention.

One might suspect that the results would be sensitive to the choice of age group over which to calculate average education, since some of the mechanisms that are thought to be relevant (see review below) involve the educational level among the relatively young, while others, which perhaps have a different strength, involve that of the older. The results from this study, based on the use of two alternative age groups (30-89 and 60-89), suggest that the choice of age group may not be critical, which would be convenient for researchers in this area However, there is always a possibility that a check of additional alternatives and a focus on other aggregate variables would have led to another conclusion.

It is also important to note that the same pattern in the estimates appeared regardless of whether the average education was lagged 0,10 or 20 years, although it would seem reasonable to expect that some of the suggested mechanisms (see below)

Table 2 Effects of average education in the municipality on individual mortality, according to various models with and without lag, among women and men aged $60-89$ in 1981-2002 (ORs with $95 \%$ Cls)

\begin{tabular}{|c|c|c|}
\hline & Women & Men \\
\hline \multicolumn{3}{|l|}{ Models of type 1} \\
\hline $\begin{array}{l}\text { A: Includes current average education among persons aged } \\
60-89 \text { in the current municipality of residence, individual } \\
\text { education and age, period and population size }\end{array}$ & $0.940^{* * *}(0.928$ to 0.952$)$ & $0.955^{* * *}(0.943$ to 0.966$)$ \\
\hline $\begin{array}{l}F: \text { As for } A \text {, but average education and population size lagged } \\
10 \text { years }\end{array}$ & $0.924^{* * *}(0.910$ to 0.938$)$ & $0.938^{* * *}(0.925$ to 0.952$)$ \\
\hline G: As for A, but observation period 1991-2002 & $0.951 * * *(0.936$ to 0.966$)$ & $0.963^{* * *}(0.948$ to 0.977$)$ \\
\hline $\begin{array}{l}\mathrm{H} \text { : As for A, but observation period } 1991-2002 \text { and average } \\
\text { education and population size lagged } 20 \text { years }\end{array}$ & $0.930^{* * *}(0.908$ to 0.953$)$ & $0.935^{* * *}(0.914$ to 0.957$)$ \\
\hline \multicolumn{3}{|l|}{ Models of type 2} \\
\hline $\begin{array}{l}\text { K: Includes current average education among persons aged } \\
60-89 \text { in the current municipality of residence, individual } \\
\text { education and age, period and municipality dummies }\end{array}$ & $0.946 *(0.890$ to 1.005$)$ & $0.686^{* * *}(0.648$ to 0.725$)$ \\
\hline $\begin{array}{l}P \text { : As for } K \text {, but average education and municipality dummies } \\
\text { lagged } 10 \text { years }\end{array}$ & 0.964 (0.911 to 1.019$)$ & $0.753^{* * *}(0.715$ to 0.792$)$ \\
\hline Q: As for K, but observation period 1991-2002 & $0.868 *(0.751$ to 1.002$)$ & $0.692^{* * *}(0.603$ to 0.795$)$ \\
\hline $\begin{array}{l}\text { R: As for K, but average education and municipality dummies } \\
\text { lagged } 20 \text { years and observation period } 1991-2002\end{array}$ & $0.933(0.810$ to 0.975$)$ & $0.826^{* *}(0.724$ to 0.943$)$ \\
\hline
\end{tabular}

${ }^{*} \mathrm{p}<0.10 ;{ }^{* *} \mathrm{p}<0.01 ;{ }^{* * *} \mathrm{p}<0.001$. 
may need time to be felt. Also this result is somewhat reassuring, since few researchers have data that allow lags to be considered, but again, one should be careful to draw general conclusions.

To identify an effect of average education with the fixedeffects approach, there must be some variation in average education within municipalities, and there must be some variation across municipalities in this within-municipality variation. If there is little such variation, it will be difficult to separate the effects of average education from the effects of the municipality and time dummies. By running a simulation experiment, one might get an idea of how large a variation one would need to obtain reasonably reliable estimates. However, this is left to future research. Given the general robustness of the findings, separation of effects is probably not a major problem in the present study.

\section{Why sex differences?}

There are many reasons why community education may influence individual mortality, net of one's own education. Some of these involve the income level in the community, which tends to be elevated as a result of higher education (and also is a determinant of education, as further addressed below), while others involve the non-economic aspects of education.

One possible mechanism is that better-educated persons in the community may have learnt about health at school; they may have become more conscious about their ability to influence their health; and their skills and credentials may have given them a higher income, in turn facilitating health-promoting activities. ${ }^{31}$ This knowledge, attitude and behaviour may be passed on to others through social interaction. ${ }^{49} \mathrm{~A}$ second possible pathway is that the higher average income resulting from higher education may contribute to a more pleasant environment, which may encourage outdoor physical activities and produce a general feeling of well-being.

Third, the level of education may affect the quality of health services. Norway has a public healthcare system that to a large extent is financed from national sources and that is subjected to national quality regulations, but when many persons in the municipality or nearby are well educated, it may be easier to recruit qualified personnel to the health facilities serving that municipality. It is also possible that higher tax incomes for a municipality may lead to a higher density of public health centres or nursing homes, or that higher purchasing power of the inhabitants may fuel the establishing of smaller private health services.

A fourth mechanism is that a high average education may increase the chance that the individual or his or her spouse has a well-paid job in the advanced service sector (and thus a high retirement pension later), which may benefit their health for several reasons. A fifth possibility is that, when other persons have better health because of better education (or the resulting high income), and therefore present less competing demand for health services, the individual under consideration may receive better help.

Finally, given one's own education, those who are surrounded by well-educated persons have a lower education relative to others than do those who are surrounded by less educated persons. It has been argued that a low relative income may produce a psychosocial stress that increases mortality, ${ }^{50-54}$ and perhaps a low relative education has a similar impact, although it is typically less visible.

Which of these mechanisms can be responsibly for the more clearly beneficial effect for men than for women that is suggested when municipality dummies were included (but not by the other models)? It is difficult to come up with a plausible answer. Men are not particularly eager users of health services, ${ }^{55}$ the argument about individual income should be relevant for both sexes, and although men tend to have a less healthy lifestyle than women, ${ }^{55}$ this does not necessarily mean that they are less conscious about their health behaviour and more susceptible to influences from others' health behaviour. Some authors have suggested that men may be more adversely affected by relative deprivation than women, ${ }^{56}$ but this should contribute to a particularly harmful effect of high average education for them.

\section{Weaknesses and limitations}

It should be noted that even the estimates from models including municipality dummies may be biased, in the sense that they may not reflect causal effects of higher average education. One reason is that the approach only controls for time-invariant unobserved factors, not the time-varying factors. For example, education may be particularly high in certain years because of a local economic boom that has stimulated industries attracting better-educated people, or-to go beyond the economic dimension-various local political changes may have had a similar effect. Such factors may influence mortality as well. Further, certain community characteristics far back in time may have affected the opportunities to take education among the currently adult population in addition to influencing their mortality.

\section{What is already known on this subject}

Earlier investigations have shown health and mortality effects of community socio-economic resources. However, the sex differences have not been clear, and the estimates may well have been biased because of inadequate control for community factors affecting both the socio-economic resources and individual health.

\section{What this study adds}

In the present study, population size was controlled and then also for all time-invariant unobserved community characteristics by including community dummies (fixed effects). Both steps had large implications for the estimates. The results from the fixedeffects models support the idea that those surrounded by welleducated people may have a lower mortality than others, net of their own education, though there is a surprisingly large difference between the sexes. The effect is significant only for men.

\section{Policy-implications}

Better assessments of effects of community socio-economic resources may be helpful to politicians and planners who make efforts to reduce health inequities. 
Selective migration may also produce a bias: people who live in the municipality when education is generally high may be different-in terms of unobserved individual characteristics-from those living there when it is low, and not as a result of the high average education, which would simply be a causal pathway, but because some characteristics may increase the chance of moving to or remaining in a place with a high level of education. For example, those who are exposed to a high average level of education may tend to have socially advantaged parents, or may for other reasons have had a strong economy in the past. ${ }^{57}$ They may also tend to have better-educated spouses, which may contribute to a lower mortality. ${ }^{34}$ Spouse's education was included in some additional models estimated only for the married and was found to explain less than $10 \%$ of the effect of municipality education. In addition to such socio-economic factors, there may be selection with respect to, for example, individual attitudes that are linked to health behaviour.

Interesting questions remain to be answered. In particular, no attempt was made in this study to see whether the effects of the average education in the municipality are non-linear, and it was not checked whether the effects vary across causes of death, as other community effects have been found to do in some studies. ${ }^{9}$ Further, it was not checked whether the effects of community education vary with the level of own education, which would accord with some $e^{37} 58$ but not all ${ }^{11}$ earlier investigations. Finally, the data did not allow consideration of smaller geographical units. It surely makes sense to focus on municipalities, where many important political decisions are taken, but there would also be good reasons for considering higher ${ }^{8-10}$ or lower ${ }^{3715}$ levels of aggregation, if possible.

Acknowledgements $\mathrm{F}$ Steele, E Biørn and three anonymous reviewers have given helpful comments.

Funding The study has been funded by the Norwegian Research Council.

Competing interests None.

Ethics approval The Data Inspectorate and the Regional Ethical Committee have approved the use of the data.

Provenance and peer review Not commissioned; externally peer reviewed.

\section{REFERENCES}

1. Pickett KE, Pearl M. Multilevel analyses of neighbourhood socioeconomic context and health outcomes. J Epidemiol Community Health 2001;55:111-22.

2. Robert SA. Socioeconomic position and health: the independent contribution of community socioeconomic context. Annu Rev Sociol 1999;25:489-516.

3. Chaix B, Rosvall M, Lynch J, et al. Disentangling contextual effects on causespecific mortality in a longitudinal 23-year follow-up study: impact of population density or socioeconomic environment. Int J Epidemiol 2006;35:633-43.

4. Chaix B, Rosvall M, Merlo J. Recent increase of neighborhood socioeconomic effects on ischemic heart disease mortality: a multilevel survival analysis of two large Swedish cohorts. Am J Epidemiol 2007;165:22-6.

5. Sundquist K, Ahlen H. Neighbourhood income and mental health: a multilevel follow-up study of psychiatric hospital admissions among 4.5 million women and men. Health Place 2006;12:594-602.

6. Sundquist K, Winkleby $\mathrm{M}$, Ahlen $\mathrm{H}$, et al. Neigborhood socioeconomic environment and incidence of coronary heart disease: a follow-up study of 25319 women and men in Sweden. Am J Epidemiol 2004;159:655-62.

7. Osler M, Christensen U, Lund R, et al. High local unemployment and increased mortality in Danish adults. Results from a prospective multilevel study. Occup Environ Med 2003;60:e16.

8. Blomgren JP, Martikainen $P$, Mäkelä $P$, et al. The effects of regional characteristics on alcohol-related mortality - a register-based multilevel analysis of 1.1. million men. Soc Sci Med 2004;58:2523-35.

9. Martikainen P, Kauppinen TM, Valkonen T. Effects of the characteristics of neighbourhoods and the characteristics of people on cause specific mortality: a register based follow-up study of 252000 men. J Epidemiol Community Health 2003;57:210-17.

10. Martikainen P, Maki N, Blomgren J. The effects of area and individual social characteristics on suicide risk: a multilevel study of relative contribution and effect modification. Eur J Popul 2004;20:323-50.
11. Turrell G, Kavanagh A, Draper D, et al. Do places affect the probability of death in Australia? A multilevel study of area-level disadvantage, individual-level socioeconomic position and all-cause mortality. J Epidemiol Community Health 2007:61:13-19.

12. Van Lenthe FJ, Borrell LN, Costa G, et al. Neighbourhood unemployment and all cause mortality: a comparison of six countries. J Epidemiol Community Health 2005;59:231-7.

13. Kavanagh M, Bentley R, Turrell G, et al. Does gender modify associations between self rated health and the social and economic characteristics of local environments. $J$ Epidemiol Community Health 2006;60:490-5.

14. Diez-Roux AV, Nieto FJ, Muntaner C, et al. Neighborhood environments and coronary heart disease: a multilevel analysis. Am J Epidemiol 1997;146:48-63.

15. Sundquist K, Malmström M, Johansson SE. Neighbourhood deprivation and incidence of coronary heart disease: a multilevel study of 2.6 million women and men in Sweden. J Epidemiol Community Health 2004;58:71-7.

16. Stafford M, Cummins S, Macintyre $S$, et al. Gender differences in the association between health and neighbourhood environment. Soc Sci Med 2005;60:1681-92

17. LeClere FB, Rogers RG, Peters KD. Ethnicity and mortality in the United States: individual and community correlates. Soc Forces 1997;76:169-98.

18. Rosenzweig MR, Wolpin KI. Evaluating the effects of optimally distributed public programs: child health and family planning interventions. Am Econ Rev 1986;76:470-82

19. Gertler P, Molyneaux JW. How economic development and family planning programs combined to reduce Indonesian fertility. Demography 1994;31:33-63.

20. Helleringer S, Kohler HP. Social networks, perceptions of risk, and changing attitudes towards HIV/AIDS: new evidence from a longitudinal study using fixed effects analysis. Popul Stud (Camb) 2005;59:265-82

21. Rindfuss RR, Guilkey D, Morgan SP, et al. Child care availability and first-birth timing in Norway. Demography 2007:44:345-72.

22. Kravdal $\boldsymbol{\emptyset}$. A fixed-effects multilevel analysis of how community family structure affects individual mortality in Norway. Demography 2007:44:519-36.

23. Mellor JM, Milyo J. Reexamining the evidence of an ecological association between income inequality and health. J Health Polit Policy Law 2001;26:487-522.

24. Mellor JM, Milyo J. 2002. Income inequality and health status in the United States Evidence from Current Population Survey. J Hum Resour 2002:37:510-39.

25. Mellor JM, Milyo J. Is exposure to income inequality a public health concern? Lagged effects of income inequality on individual and population health. Health Serv Res 2003;38:137-52

26. Beckfield J. Does income inequality harm health? New cross-national evidence. $J$ Health Soc Behav 2004:45:231-48.

27. Folland S. Does 'community social capital' contribute to population health? Soc Sci Med 2007:64:2342-54

28. Scheffler RM, Brown TT, Rice JK. The role of social capital in reducing non-specific psychological distress: the importance of controlling for omitted variable bias. Soc Sci Med 2007:65:842-54.

29. Statistics Norway. Life tables 2009. http://www.ssb.no/english/subjects/02/02/ 10/dode en/tab-2010-04-15-05-en.html.

30. Zajacova A. Education, gender, and mortality: does schooling have the same effect on mortality for men and women in the US? Soc Sci Med 2006;63:2176-90.

31. Ross CE, Mirowsky J. Refining the association between education and health: the effects of quantity, credential, and selectivity. Demography 1999;36:445-60.

32. Kunst AE, Mackenbach JP. The size of mortality differences associated with educational level in nine industrialized countries. Am J Public Health 1996;84:932-7.

33. Kravdal Ø. Does place matter for cancer survival in Norway? A multilevel analysis of the importance of hospital affiliation and municipality socio-economic resources. Health Place 2006;12:527-37.

34. Kravdal $\boldsymbol{\varnothing}$. A broader perspective on education and mortality: are Norwegian men and women influenced by other people's education? Soc Sci Med 2008;66:620-36

35. Wen M, Browning CR, Cagney KA. Poverty, affluence, and income inequality: neighborhood economic structure and its implications for health. Soc Sci Med 2003:57:843-60

36. Wight RG, Aneshensel CS, Miller-Martinez D, et al. Urban neighborhood context, educational attainment, and cognitive function among older adults. Am J Epidemiol 2006:163:1071-8.

37. Winkleby $\mathbf{M}$, Cubbin $\mathrm{C}$, Ahn D. Effect of cross-level interaction between individual and neighbourhood socioeconomic status on adult mortality rates. Am J Public Health 2006;96:2145-53.

38. Lee RE, Cubbin C, Winkelby M. Contribution of neighbourhood socioeconomic status and physical activity resources to physical activity among women. J Epidemio Community Health 2007:61:882-90.

39. Geronimus AT, Bound J. Use of census-based aggregate variables to proxy for socioeconomic group: evidence from national samples. Am J Epidemiol 1998;148:475-86.

40. Blakely TA, Kennedy BP, Glass R, et al. What is the lag time between income inequality and health status? J Epidemiol Community Health 2000;54:318-19.

41. Subramanian SV, Kawachi I. Whose health is affected by income inequality? A multilevel interaction analysis of contemporaneous and lagged effects of state income inequality on individual self-related health in the United States. Health Place 2006;12:141-56 
42. Kravdal Ø. Does income inequality really influence individual mortality? Results from a fixed-effects analysis where constant unobserved municipality characteristics are controlled. Demogr Res 2008;18:205-32. http://www.demographic-research.org/ Volumes Nol18/7.

43. Schneider TAB, Bosker RJ. Multilevel analysis. London: Sage, 1999.

44. Statistics Norway. Norwegian Standard Classification of Education. Revised 2000 Official Statistics of Norway C 617. Norway: Oslo-Kongsvvinger, 2001.

45. Islam MK, Merlo J, Kawachi I, et al. Does it really matter where you live? A panel data multilevel analysis of Swedish municipality-level social capital on individual health-related quality of life. Health Econ Policy Law 2006;1:209-35.

46. Ellaway A, Macintyre S. Women in their place. Gender and perceptions of neighbourhoods and health in the west of Scotland. In: Dyck I, Lewis DN, McLafferty S, eds. Geographies of women's health. London: Routledge, 2001:265-81.

47. Molinari C, Ahern M, Hendryx M. The relationship of community quality to the health of women and men. Soc Sci Med 1998;47:1113-20.

48. Sundquist J, Johansson SE, Yang M, et al. Low linking social capital as a predictor of coronary heart disease in Sweden: a cohort study of 2.8 million people. Soc Sci Med 2006;62:954-63.

49. Montgomery MR, Casterline JB. Social learning, social influence and new models of fertility. Popul Dev Rev 1996;22(Suppl):151-75.
50. Kawachi I, Subramanian SV, Almeida-Filho N. A glossary for health inequalities. $J$ Epidemiol Community Health 1002;56:647-52.

51. Lynch J, Davey Smith G, Harper $\mathrm{S}$, et al. Is income inequality a determinant of population health? Part 1. A systematic review. Milbank 0 2004:82:5-99.

52. Wilkinson RG. Socioeconomic determinants of health: health inequalities: relative or absolute material standards? BMJ 1997;314:591-5.

53. Wagstaff $\mathbf{A}$, van Doorslaer E. Income inequality and health: what does the literature tell us? Annu Rev Public Health 2000;21:543-67.

54. Elstad JI, Dahl E, Hofoss D. Associations between relative income and mortality in Norway: a register-based study. Eur J Public Health 2006;16:640-4.

55. Department of Social Affairs and Health. Kvinners Helse i Norge. NOU 1999:13. Statens forvaltningstienete, Statens trykking: Oslo, 1999

56. Yngwe MÅ, Fritzell J, Lundberg 0, et al. Exploring relative deprivation: is social comparison a mechanism in the relationship between income and health? Soc Sci Med 2003:57:1463-73.

57. Næss Ø, Leyland AH, Davey Smith G, et al. Contextual effect on mortality of neighbourhood level education explained by earlier life deprivation. J Epidemiol Community Health 2005;59:1058-9.

58. Blomgren J, Valkonen T. Characteristics of urban regions and all-cause mortality in working-age population: effects of social environment and interactions with individual unemployment. Demogr Res 2007;15:109-34. 